\title{
Real-time magnetic resonance imaging guidance improves the yield of endomyocardial biopsy
}

\author{
Toby Rogers ${ }^{1 *}$, Kanishka Ratnayaka ${ }^{1,2}$, Parag Karmarkar ${ }^{4}$, William Schenke ${ }^{1}$, Jonathan R Mazal ${ }^{1}$, \\ Adrienne E Campbell-Washburn ${ }^{1}$, Ozgur Kocaturk ${ }^{1,3}$, Anthony Z Faranesh ${ }^{1}$, Robert J Lederman ${ }^{1}$ \\ From 19th Annual SCMR Scientific Sessions \\ Los Angeles, CA, USA. 27-30 January 2016
}

\section{Background}

In current practice, the diagnostic yield of endomyocardial biopsy is low because the procedure is performed 'blind' using X-ray fluoroscopy guidance and because many pathologies affect the myocardium in a patchy distribution. We hypothesized that biopsy performed under direct realtime MRI guidance would have superior diagnostic yield, in an animal model of focal myocardium pathology.

\section{Methods}

An active visualization MR conditional bioptome was designed and built for transcatheter endomyocardial biopsy (MRI Interventions, Irvine, CA). A porcine model of focal myocardial pathology that enhances with late gadolinium enhancement imaging and that contained fluorescent tags that are easily identifiable under ultraviolet light was created. Under X-ray fluoroscopy, selective coronary artery catheterization was performed and $3 \mathrm{~mL}$ of fluorescent microspheres (NuFlow Hydrocoat, $15 \mu \mathrm{m}$ diameter, 5 million spheres $/ \mathrm{mL}$ ) was infused, followed by $2 \mathrm{~mL}$ of $100 \%$ ethanol to create a focal lesion. Animals were survived for min 7 days, after which each animal underwent both MRI and X-ray guided biopsy. Specimens were analysed using a Leica MZFIII dissecting microscope under transmitted or ultraviolet light with a $400-480 \mathrm{~nm}$ band pass filter.

\section{Results}

The bioptome shaft was actively visualized under realtime MR imaging. The jaws appeared as a distinct signal void (arrow, Figure 1A). After administration of systemic gadolinium contrast, the lesion was visible using LGE or inversion recovery real-time MRI (Figure 1B). The bioptome was navigated to the pathology and specimens were collected. Animals were then transferred to an $\mathrm{X}$-ray catheterization laboratory, where 'conventional' fluoroscopy guided biopsy was performed. Examination of the biopsy specimens under ultraviolet light revealed fluorescent microspheres in 24/27 specimens obtained using MRI guidance compared with $7 / 28$ specimens obtained using X-ray fluoroscopy guidance (Figure 2).

\section{Conclusions}

Endomyocardial biopsy under direct real-time MRI guidance using an active visualization MRI-conditional bioptome is feasible. Using this bioptome we demonstrate targeted biopsy of focal myocardial pathology. Compared with X-ray fluoroscopy guided endomyocardial biopsy, MRI guidance substantially improves the diagnostic yield in an animal model of focal myocardial pathology.

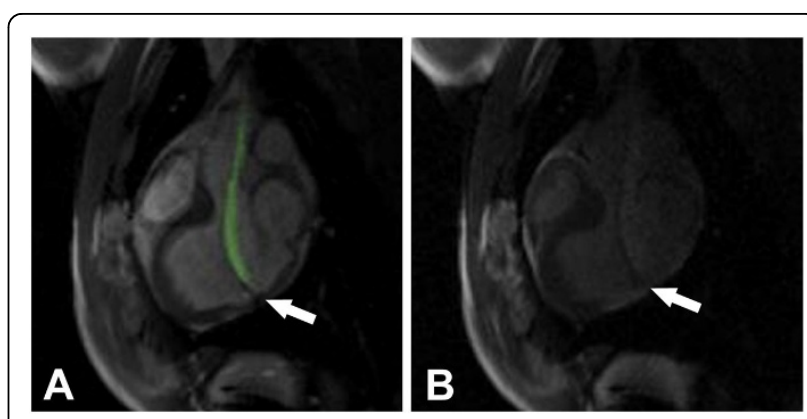

Figure 1 Real-time MRI guided endomyocardial biopsy using an active visualization bioptome. 

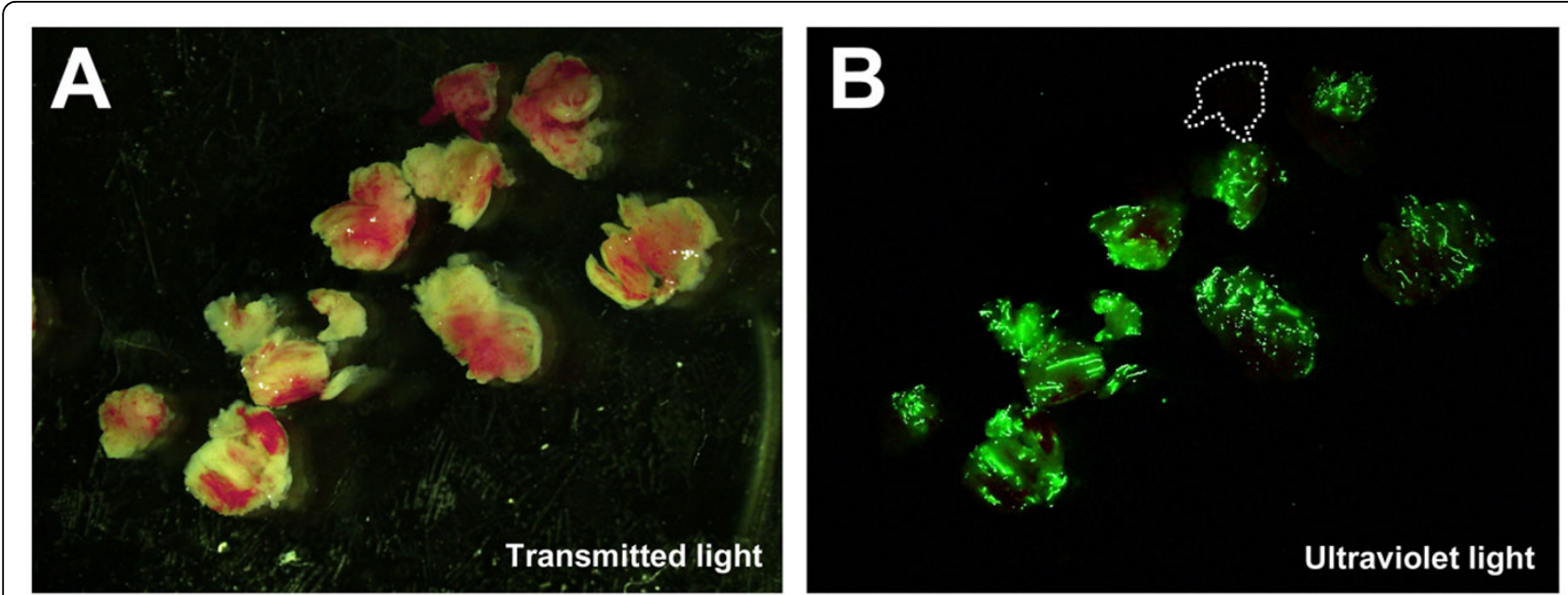

\section{Endomyocardial biopsy under X-ray fluoroscopy guidance}
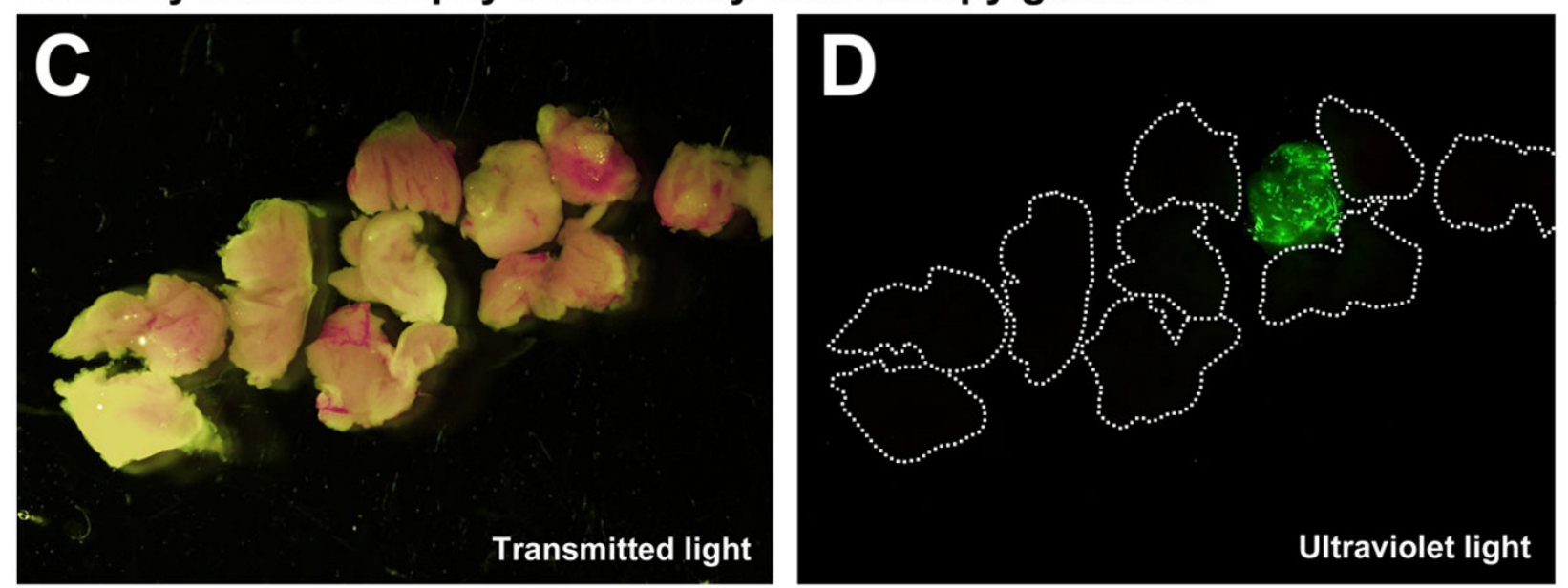

Figure 2 Biopsy specimens under transmitted and ultraviolet light obtained using either real-time MRI or X-ray fluoroscopy guidance.

\section{Authors' details}

${ }^{1}$ National Heart Lung and Blood Institute, National Institues of Health

Bethesda, MD, USA. ${ }^{2}$ Department of Cardiology, Children's National Medical Center, Washington, DC, USA. ${ }^{3}$ Institute of Biomedical Engineering, Bogazici University, Istanbul, Turkey. ${ }^{4}$ Russell H Morgan Department of Radiology and Radiological Sciences, Johns Hopkins University, Baltimore, MD, USA.

Published: 27 January 2016

doi:10.1186/1532-429X-18-S1-Q69

Cite this article as: Rogers et al:: Real-time magnetic resonance imaging

guidance improves the yield of endomyocardial biopsy. Journal of

Cardiovascular Magnetic Resonance 2016 18(Suppl 1):Q69.
Submit your next manuscript to BioMed Central and take full advantage of:

- Convenient online submission

- Thorough peer review

- No space constraints or color figure charges

- Immediate publication on acceptance

- Inclusion in PubMed, CAS, Scopus and Google Scholar

- Research which is freely available for redistribution 